Article

\title{
Vibroacoustic Prediction of a High-Temperature Superconducting Field-Modulation Double-Stator Machine with Stationary Seal
}

\author{
Yubin Wang ${ }^{1}$, Chenchen Zhao ${ }^{1}$, Wei $\mathrm{Xu}^{1}$ and Xiaodong Zhang ${ }^{2, *}$ \\ 1 College of Information and Control Engineering, China University of Petroleum (East China), \\ Qingdao 266580, China; wangyubin@upc.edu.cn (Y.W.);ZHCC_UPC@s.upc.edu.cn (C.Z.); \\ XuWei0914@s.upc.edu.cn (W.X.) \\ 2 Shenzhen in Drive Amperex Co. Ltd., Shen Zhen 518000, China \\ * Correspondence: zhangxiaodong@indrive.onaliyun.com; Tel.: +86-150-1281-8289
}

Received: 29 August 2018; Accepted: 21 September 2018; Published: 26 September 2018

\begin{abstract}
This paper predicted the vibroacoustic regularity of a high temperature superconducting (HTS) field-modulation double-stator (HTS-FMDS) machine with stationary seal for low-speed and direct-drive applications. The originality of this paper lies in that the spatial order and angular velocity of electromagnetic-force density of the HTS-FMDS machine were derived by using the analytical method. Moreover, the validity of the analytical solutions was verified by the finite element analysis (FEA) results. Then, the modal shapes and frequencies of the outer stator were obtained by using multiphysics coupling simulation. By transferring the electromagnetic force to the stator structural model, the regularity of electromagnetic vibration and noise of the HTS-FMDS machine were revealed.
\end{abstract}

Keywords: high-temperature superconducting; field-modulation; double-stator; vibroacoustic; electromagnetic force density; finite element analysis

\section{Introduction}

In recent years, high-temperature superconducting (HTS) machines have been paid widespread attention in high-power, low-speed, and direct-drive applications such as offshore wind power generation and marine propulsion since they offer the merits of high efficiency and high power/torque density [1-3]. Generally, the HTS field coils are wound by HTS wires and supplied with direct-current to obtain the excitation field and are mounted on the rotor side. Therefore, the coupling device for cryogenic transfer is installed between the rotating rotor and stationary refrigeration system to keep the HTS field coils operating at cryogenic temperature needed by superconductor properties of HTS wires through the circulation of refrigeration coolant. According to whether the coupling device for cryogenic transfer is employed to cool the HTS field-excitation coils, the HTS machines can be divided into two categories, namely, the rotating seal and stationary seal HTS machines. For the rotating HTS machines, since the HTS field-excitation coils are mounted on the rotating rotor side, it is necessary to use the coupling device for cryogenic transfer so that the superconducting state of HTS field-excitation coils can be maintained [4-7]. On the contrary, the HTS field-excitation coils of the latter are installed in the stationary stator side, and thus the circulation of the refrigeration coolant in the cooling system can be performed by using stationary seal [8-10]. Accordingly, the manufacturing cost and difficulty of superconducting machines with stationary seal can be decreased effectively.

Under the condition of superconducting state, the HTS wires have zero resistance characteristics. Therefore, the HTS field-excitation coils can provide a strong excitation field by applying high direct-current. However, the high air-gap flux density of HTS machines will produce strong electromagnetic force that 
varies with time and space. When the radial component of this electromagnetic force acts on the surface of stator-core teeth, the stator core will be vibrated and deformed, which causes pulsation of the surrounding air, hence generating electromagnetic acoustic noise. In particular, if the orders of electromagnetic force waves are consistent with those of the stator modal shapes and the frequencies are very close to those of stator modal shapes, the stator resonance of the HTS machine will be caused, which generates greater electromagnetic acoustic noise.

In the last decades, many literatures have reported their research results on electromagnetic vibration and acoustic noise of conventional machines, such as switched reluctance motors (SRMs) [11-13], claw pole machines [14,15], induction motors (IMs) [16,17], and permanent magnet synchronous motors (PMSMs) $[18,19]$. However, few literatures investigated the electromagnetic vibration and acoustic noise of HTS machines. Especially for the HTS field-modulation double-stator (HTS-FMDS) machine with stationary seal, due to the magnetic field modulation by the modulation-ring rotor and both the inner and outer stator teeth, the magnetic fields of both inner and outer air-gaps are rich in harmonic components, which makes the electromagnetic force analysis of these kinds of HTS machines more complicated. Therefore, the purpose of this paper is to analyze the electromagnetic vibration and acoustic noise of the HTS machines with double air-gaps and double stators to obtain the vibro-acoustic regularity, thus providing a prediction for the prototype design of HTS machines. Moreover, in this paper, we only focus on the electromagnetic vibration and acoustic noise of HTS-FMDS machine. In Section 2, the analytical expression of electromagnetic force in a double-stator HTS machine were discussed. Section 3 focused on the finite element analysis (FEA) of electromagnetic force. Then, in Section 4, the stator modal shapes of the double-stator HTS machine were presented and analyzed, and the electromagnetic vibration and acoustic noise of the double-stator HTS machine was investigated by FEA. Finally, some conclusions were drawn in Section 5.

\section{Analysis of Electromagnetic Force}

The configurations of the HTS-FMDS machine are shown in Figure 1. It mainly contains an outer stator, a modulation-ring rotor, a ferromagnetic ring, and an inner stator from the outside to the inside. The outer stator has 42 slots and the number of pole-pairs of the three-phase armature-windings is 14 . While the HTS field-excitation windings with four pairs of magnetic poles are placed on the inner stator side so that the armature windings and the HTS field-excitation windings are located in two spatially independent stators. In order to modulate both the inner and outer air-gap magnetic-field and transmit electromagnetic torque, a modulation-ring rotor, which consists of 18 ferromagnetic blocks, is mounted between the inner and outer stators. It should be particularly noted that the ferromagnetic ring, which is located on the top of each field-excitation magnetic pole, not only provides a magnetic circuit for the field-excitation magnetic field, but also guides a path for the armature-reaction magnetic field. Based on field-modulation theory, the sinusoidal back-EMF can be induced in the armature windings of the outer stator since the stationary HTS field-excitation magnetic-field is modulated by the rotating modulation-ring rotor. Its operating principle has been introduced in detail in Reference [20]. Since the HTS-FMDS machine has two stators and double air-gaps, the electromagnetic force, which is generated by the interaction of harmonic components of both excitation field and armature-reaction magnetic-field, will be exerted to both the inner surface of the outer stator teeth and the outer surface of the inner stator teeth and causes electromagnetic vibration and acoustic noise. For the outer air-gap magnetic field, it is generated by the interaction between the armature-reaction magnetic field and the HTS excitation-field modulated by the modulation-ring rotor, while the inner air-gap magnetic field is produced by the interaction of a HTS excitation-field and the armature-reaction magnetic field modulated by the modulation-ring rotor. It should be noted that the main harmonic components of flux density of the inner air-gap are same as those of the outer air-gap, although the amplitudes of harmonic magnetic field components of the inner air-gap are different with those of the outer air-gap. By using Fourier transform, the flux density excited by HTS field-excitation magnetomotive force can be written as [21-27]: 


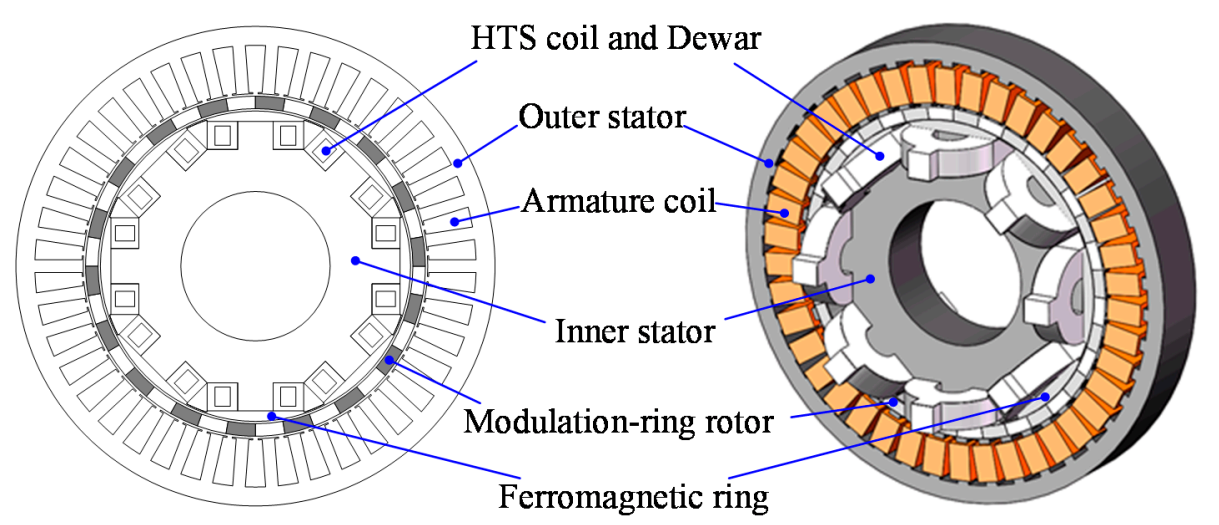

Figure 1. Configurations of the HTS-FMDS machine.

$$
\begin{gathered}
B_{r f}(\theta, t)=\sum_{j=1,3,5 \ldots}^{+\infty}\left\{\lambda_{\text {ring }, 0} F_{j} \cos \left(j P_{s c} \theta\right)\right\}+ \\
+\frac{1}{2} \sum_{j=1,3,5 \ldots}^{+\infty} \sum_{i=1}^{+\infty}\left\{F_{j} \lambda_{\text {ring }, i} \cos \left[\left(j P_{s c}+i N_{r}\right)\left(\theta-\frac{i N_{r} \omega_{r} t-i N_{r} \theta_{0}}{j P_{s c}+i N_{r}}\right)\right]\right\} \\
+\frac{1}{2} \sum_{j=1,3,5 \ldots}^{+\infty} \sum_{i=1}^{+\infty}\left\{F_{j} \lambda_{\text {ring, }, i} \cos \left[\left(j P_{s c}-i N_{r}\right)\left(\theta+\frac{i N_{r} \omega_{r} t-i N_{r} \theta_{0}}{j P_{s c}-i N_{r}}\right)\right]\right\}
\end{gathered}
$$

where $\theta$ is the mechanical angle of rotor position, $t$ is the time, $P_{s c}$ is the number of pole pairs of the HTS excitation field, $\lambda_{\text {ring, } 0}$ is the DC permeance component of modulation-ring rotor, $F_{j}$ is the amplitude of the $j$ th harmonic of HTS field-excitation magnetomotive force, $N_{r}$ is the numbers of poles of modulation-ring rotor, $\omega_{r}$ is the mechanical angular velocity of rotor, and $\lambda_{\text {ring, } i}$ is the $i$ th harmonic amplitude of permeance component of modulation-ring rotor. Similarly, the flux density generated by armature-reaction magnetomotive force can be expressed as:

$$
\begin{gathered}
B_{r a}(\theta, t)=\frac{3}{2} \sum_{v=1}^{+\infty}\left[\lambda_{\text {ring, }, 0} F_{\phi v} \cos \left(N_{r} \omega_{r} t+v k P_{s a} \theta+\varphi_{0}-\frac{\pi}{2}\right)\right] \\
+\frac{3}{4} \sum_{v=1}^{+\infty} \sum_{i=1}^{+\infty} F_{\phi v} \lambda_{\text {ring }, i} \cos \left[\left(v k P_{s a}+i N_{r}\right)\left(\theta-\frac{(i-1) N_{r} \omega_{r} t-i N_{r} \theta_{0}-\varphi_{0}+\frac{\pi}{2}}{v k P_{s a}+i N_{r}}\right)\right] \\
+\frac{3}{4} \sum_{v=1}^{+\infty} \sum_{i=1}^{+\infty} F_{\phi v} \lambda_{r i n g, i} \cos \left[\left(v k P_{s a}-i N_{r}\right)\left(\theta+\frac{(i+1) N_{r} \omega_{r} t-i N_{r} \theta_{0}+\varphi_{0}-\frac{\pi}{2}}{v k P_{s a}-i N_{r}}\right)\right]
\end{gathered}
$$

where $P_{s a}$ is the number of pole pairs of the armature-reaction magnetic field, $F_{\phi v}$ is the amplitude of the $v$ th harmonic of armature-reaction magnetomotive-force, and $\theta_{0}$ is the initial rotor position. In addition, $k$ meets the following limitation:

$$
k=\left\{\begin{array}{c}
-1 v=3 n-2 \\
1 \quad v=3 n-1 \\
v \neq 3 n
\end{array} \quad(n=1,2,3 \ldots \ldots)\right.
$$

where $n$ is a natural number. Then, ignoring the influence of the slots opening of the inner and outer stator on the air-gap flux-density, the flux density of both inner and outer air-gaps can be expressed as:

$$
B_{r}(\theta, t)=B_{r f}(\theta, t)+B_{r a}(\theta, t)
$$

Accordingly, the radial component of the electromagnetic force, which exerts on the surface of both the inner and outer stator teeth, can be calculated as follows by using Maxwell stress method:

$$
f_{r}(\theta, t) \approx \frac{B_{r}(\theta, t)^{2}}{2 \mu_{0}}
$$


where $\mu_{0}$ is the air magnetic permeability, equaling to $4 \times 10^{-7} \mathrm{H} / \mathrm{m}$. Substituting Equation (4) into Equation (5), the radial component of the electromagnetic force can be further expressed as:

$$
f_{r}(\theta, t) \approx \frac{B_{r f}(\theta, t)^{2}+B_{r a}(\theta, t)^{2}+2 B_{r a}(\theta, t) B_{r f}(\theta, t)}{2 \mu_{0}}
$$

Substituting Equation (1) and Equation (2) into Equation (6), the first term $B_{r f}(\theta, t)^{2}$, in its numerator, can be expressed as Equation (A1), the second term $B_{r a}(\theta, t)^{2}$ of the numerator can be calculated as Equation (A2), and the third term $B_{r a}(\theta, t) B_{r f}(\theta, t)$ of the numerator can be obtained as Equation (A3), where Equations (A1)-(A3) are listed in the Appendix.

According to Equations (A1)-(A3), the source, spatial order and angular velocity of the radial force density can be calculated as listed in Table 1. According to Table 1, three conclusions can be derived. Firstly, the interaction of any two harmonic components of air-gap magnetic field will produce electromagnetic force exerted on the inner and outer stator teeth. Secondly, the $(j \pm J) P_{s c}$ th and $(v+V) k P_{s a}$ th orders harmonic components of electromagnetic forces, which are excited by the interaction of harmonic components of HTS excitation magnetic field and armature-reaction magnetic field, respectively, are stationary. Thirdly, the radial electromagnetic forces are rich in harmonic components due to magnetic field modulation by the magnetic-ring rotor, although the influence of the slot opening of both the inner and outer stator on the air-gap flux-density is ignored.

Table 1. Source, spatial order, and angular velocity of electromagnetic force density.

\begin{tabular}{ccc}
\hline Source & Spatial Order & Angular Velocity \\
\hline \multirow{3}{*}{ Harmonic components of excitation field } & $(j \pm J) P_{s c}$ & 0 \\
& $(j \pm J) P_{s c}+(i \pm I) N_{r}$ & $-(i \pm I) N_{r} \omega_{r}$ \\
& $(j \pm J) P_{s c} \pm i N_{r}$ & $\mp i N_{r} \omega_{r}$ \\
\hline Harmonic components of armature-reaction & $(v+V) k P_{s a}$ & $2 N_{r} \omega_{r}$ \\
magnetic field & $(v-V) k P_{s a}$ & 0 \\
& $(v+V) k P_{s a} \pm i N_{r}$ & $\mp(i \mp 2) N_{r} \omega_{r}$ \\
& $(v+V) k P_{s a}+(i \pm I) N_{r}$ & $-(i \pm I-2) N_{r} \omega_{r}$ \\
& $(v-V) k P_{s a}+(i \mp I) N_{r}$ & $-(i \mp I) N_{r} \omega_{r}$ \\
& $(v-V) k P_{s a}-(i+I) N_{r}$ & $(i+I+2) N_{r} \omega_{r}$ \\
Interaction between the harmonic & $j P_{s c} \pm v k P_{s a}$ & $(i-I) N_{r} \omega_{r}$ \\
\hline field and excitation field & $j P_{s c} \pm\left(v k P_{s a}+i N r\right)$ & $\mp(i-1) N_{r} \omega_{r}$ \\
& $j P_{s c} \pm\left(v k P_{s a}-i N r\right)$ & $\pm(i+1) N_{r} \omega_{r}$ \\
& $j P_{s c}+i N r \pm v k P_{s a}$ & $-(i \mp 1) N_{r} \omega_{r}$ \\
& $j P_{s c} \pm(i \pm I) N r+v k P_{s a}$ & $(i \pm I-1) N_{r} \omega_{r}$ \\
& $j P_{s c}+(i \mp I) N r-v k P_{s a}$ & $(i \mp I+1) N_{r} \omega_{r}$ \\
& $j P_{s c}-i N r \pm v k P_{s a}$ & $(i \pm 1) N_{r} \omega_{r}$ \\
\hline
\end{tabular}

\section{Finite Element Analysis of Electromagnetic Force}

Since the HTS-FMDS machine has symmetrical structure in the axial direction, the two-dimensional finite element method is used to analyze its electromagnetic force. Its key size parameters are listed, as shown in Table 2. Considering that the electromagnetic properties of the HTS-FMDS machine have been investigated in detail in previously published literature [20], in this section, we will only focus on investigation of the electromagnetic force density. 
Table 2. Key size parameters of the HTS-FMDS machine.

\begin{tabular}{cc}
\hline Parameters & Value \\
\hline Number of outer stator teeth & 42 \\
Number of inner stator teeth & 8 \\
Number of pole pairs of armature windings & 14 \\
Number of pole pairs of field-excitation windings & 4 \\
Number of modulation-ring rotor teeth & 18 \\
Stator outside diameter of outer stator $(\mathrm{mm})$ & 760 \\
Stator inside diameter of outer stator $(\mathrm{mm})$ & 546.4 \\
Stator outside diameter of inner stator $(\mathrm{mm})$ & 504 \\
Stator inside diameter of inner stator $(\mathrm{mm})$ & 240 \\
Rotor outside diameter $(\mathrm{mm})$ & 42 \\
Stack length (mm) & 100 \\
Inner air-gap length $(\mathrm{mm})$ & 0.6 \\
Outer air-gap length $(\mathrm{mm})$ & 0.6 \\
Number of phases & 3 \\
\hline
\end{tabular}

\subsection{Magnetic Flux Density}

When the HTS-FMDS machine operates with no load, its air-gap magnetic field is only generated by the HTS excitation magnetomotive force. According to Equation (1), the inner and outer air-gap flux-density should include the 4th, 12th, 14th, 22nd, 32nd, 40th, 50th, and 58th harmonic components when the following conditions are met:

$$
\left\{\begin{array}{l}
j P_{s c}=4 \text { and } 12(j=1,3) \\
\left|j P_{s c} \pm i N_{r}\right|=14,22,32,40,50 \text { and } 58(j=1, i=1,2,3)
\end{array}\right.
$$

In order to verify the correctness of the theoretical analysis in Section 2, the flux density waveforms and their Fourier decomposition of inner and outer air-gaps are illustrated in Figure 2. From Figure 2b,d, it can be found that the analytically calculated harmonic components are consistent with those by using FEA, which are shown with red lines. In addition, the harmonic components depicted with blue lines, whose amplitude is greater than $0.05 \mathrm{~T}$, are mainly modulated by the outer stator teeth.

Under on-load condition, the magnetic field in the inner and outer air-gaps is generated by the interaction between the field-excitation magnetomotive force and armature-reaction magnetomotive force. The order of harmonic components of air-gaps flux-density generated by the armature reaction magnetomotive force can be expressed as:

$$
\left\{\begin{array}{l}
v k P_{s a}=14(v=1, \mathrm{k}=-1) \\
\left|v k P_{s a} \pm i N_{r}\right|=4,22,32,40,50 \text { and } 68(v=1, \mathrm{k}=-1, i=1,2,3) \\
\left|v k P_{s a} \pm i N_{r}\right|=8,10,26,46,64 \text { and } 82(v=2, \mathrm{k}=1, i=1,2,3)
\end{array}\right.
$$

Thus, ignoring the effects of magnetic saturation, new components are added to the magnetic flux density of both the inner and outer air-gaps, namely, they are the 8th, 10th, 26th, 28th, and 46th harmonic components, which are shown in Figure $3 \mathrm{~b}$,d. It should be noted that the FEA results contain harmonic components that do not appear in the theoretical calculation as denoted with blue line in both Figures 2 and 3 since the modulation effect by the outer stator teeth were neglected in the theoretical calculation. 


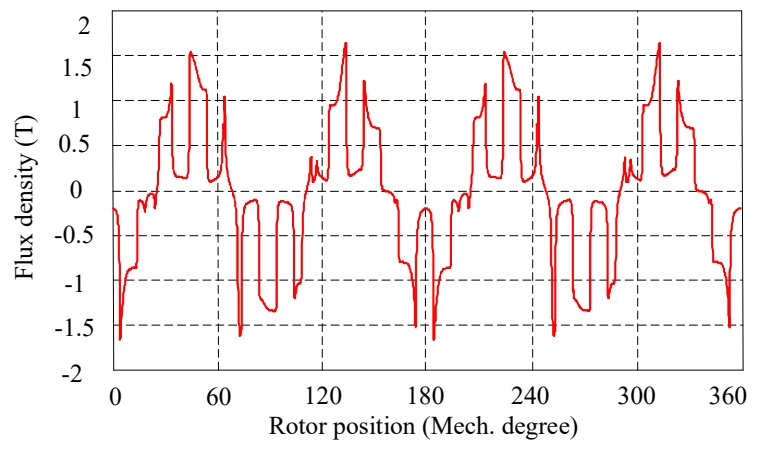

(a)

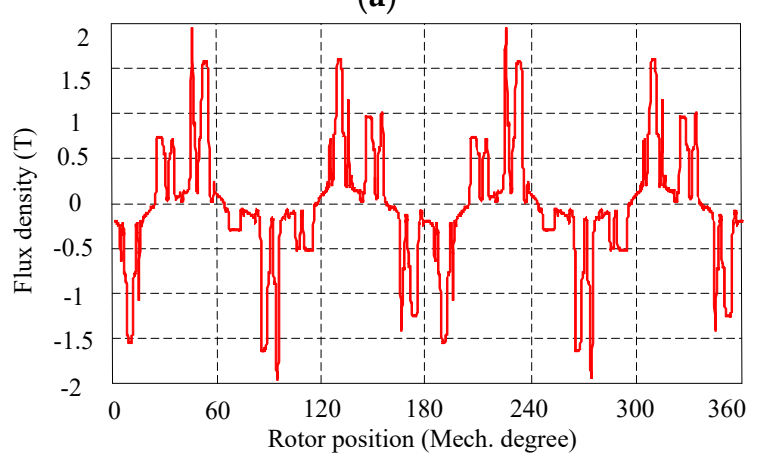

(c)

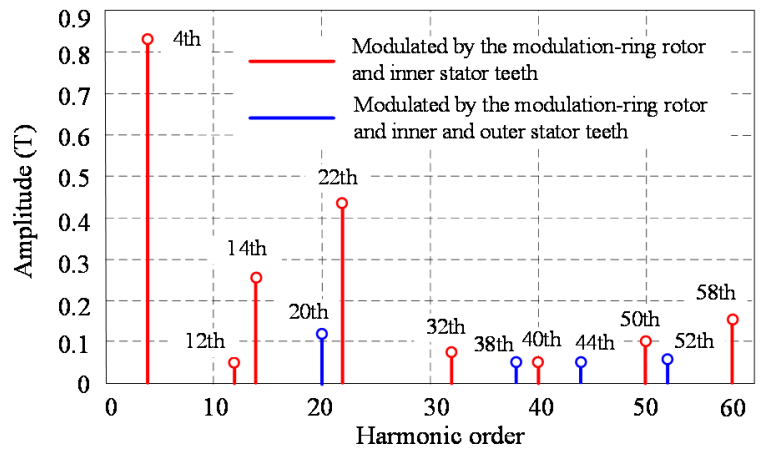

(b)

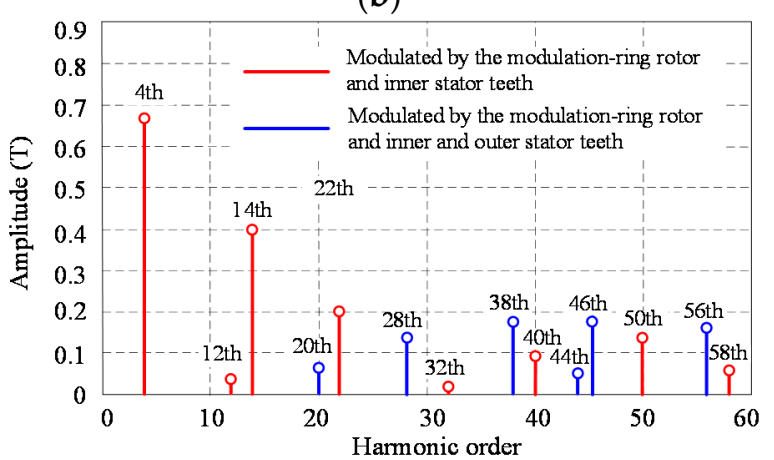

(d)

Figure 2. Magnetic flux density with no load: (a) Flux density of inner air-gap; (b) Harmonic order of flux density of inner air-gap; (c) Flux density of outer air-gap; and (d) Harmonic order of flux density of outer air-gap.

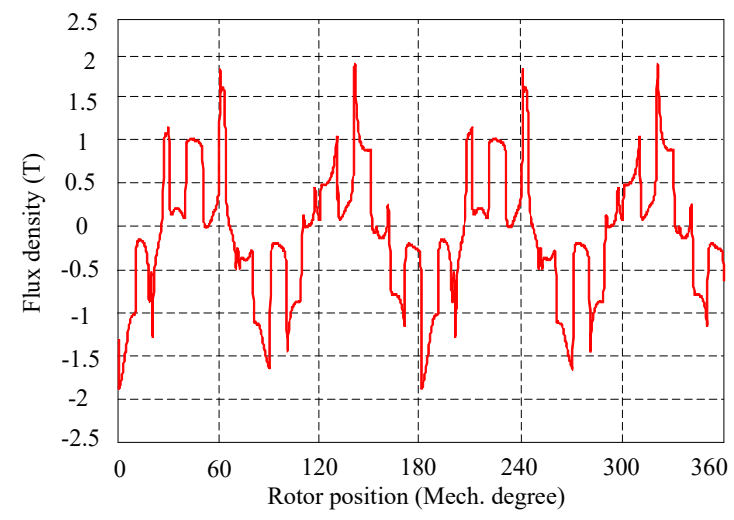

(a)

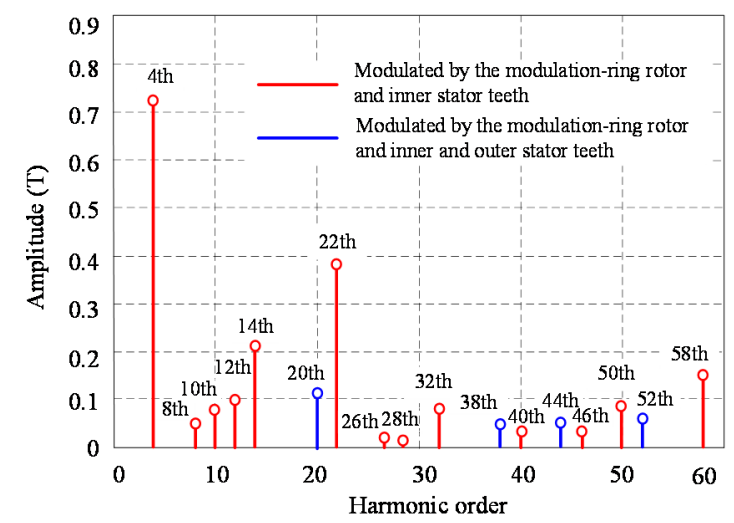

(b)

Figure 3. Cont. 


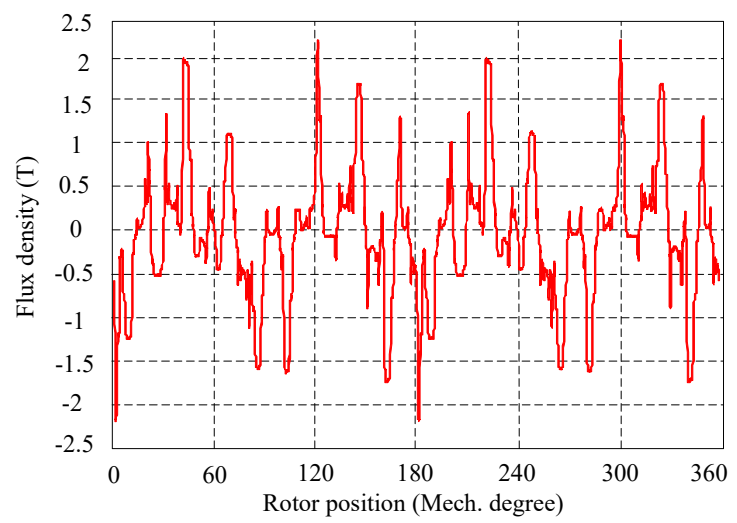

(c)

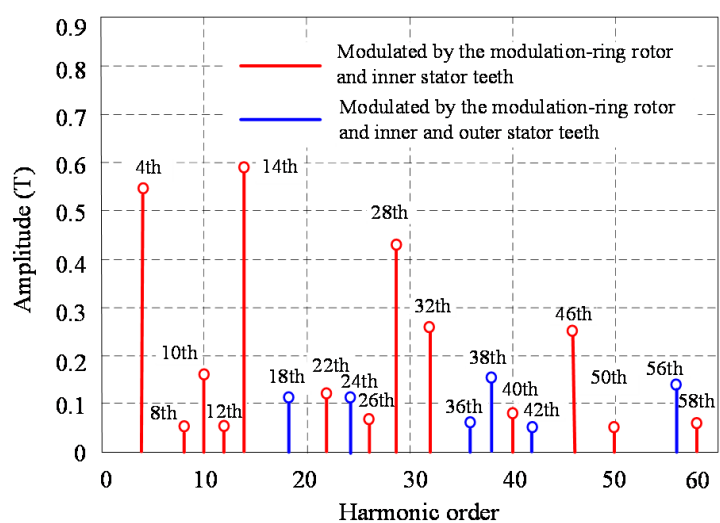

(d)

Figure 3. Magnetic flux density with on-load: (a) Flux density of inner air-gap; (b) Harmonic order of flux density of inner air-gap; (c) Flux density of outer air-gap; and (d) Harmonic order of flux density of outer air-gap.

\subsection{Electromagnetic Force Density}

As shown in Figure 4, the electromagnetic force acting on both inner and outer stators is a function of time and space. Based on Equations (A1)-(A3), the amplitudes of sequential harmonic components with different spatial orders of electromagnetic force density are determined by those of the air-gaps flux-density. Taking the electromagnetic force acting on the surface of the outer stator teeth under on-load condition, as an example, whose sequential and spatial harmonic components are depicted in Figure 5, its spatial harmonic components mainly include even harmonics. Moreover, the sequential harmonic components with the same frequency contain various spatial harmonic components with different orders, and vice versa. Among the spatial harmonic components, the zero order component is mainly caused by the interactions between the harmonic components with the same order of excitation field and the interactions between the harmonic components with the same order of armature-reaction magnetic field, respectively. According to Table 1, the zero order harmonic component is not only independent of the spatial position, but also independent of the time variable. Thus, it will not contribute to the vibration and noise of the HTS machine, although its magnitude reaches to $230 \mathrm{~N} / \mathrm{m}^{2}$. Moreover, compared with the 18th, 24th, 28th, 32th, 36th, and 42th harmonic components, which is the amplitude of the low-order harmonic components, which offers major contributions to electromagnetic noise and is relatively low.

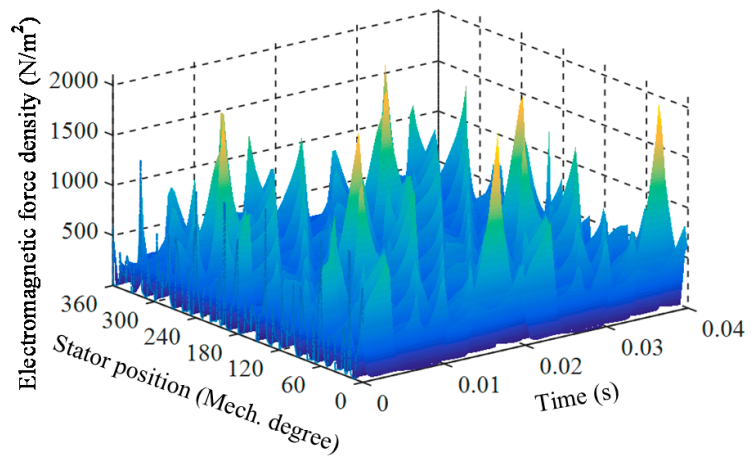

(a)

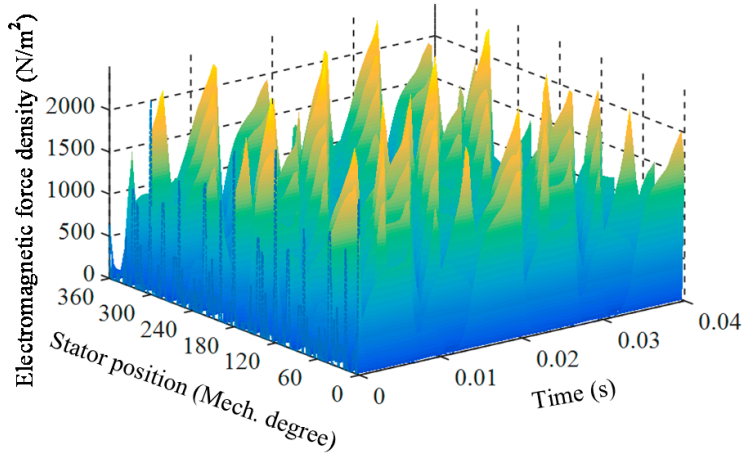

(b)

Figure 4. Electromagnetic force density on-load: (a) Inner stator; and (b) outer stator. 


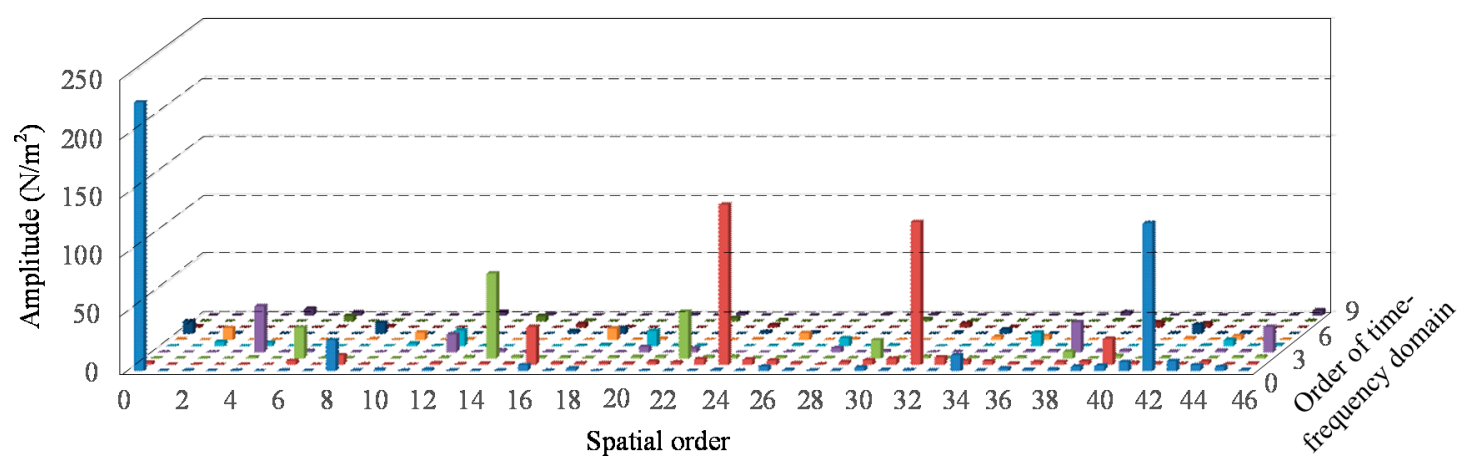

(a)

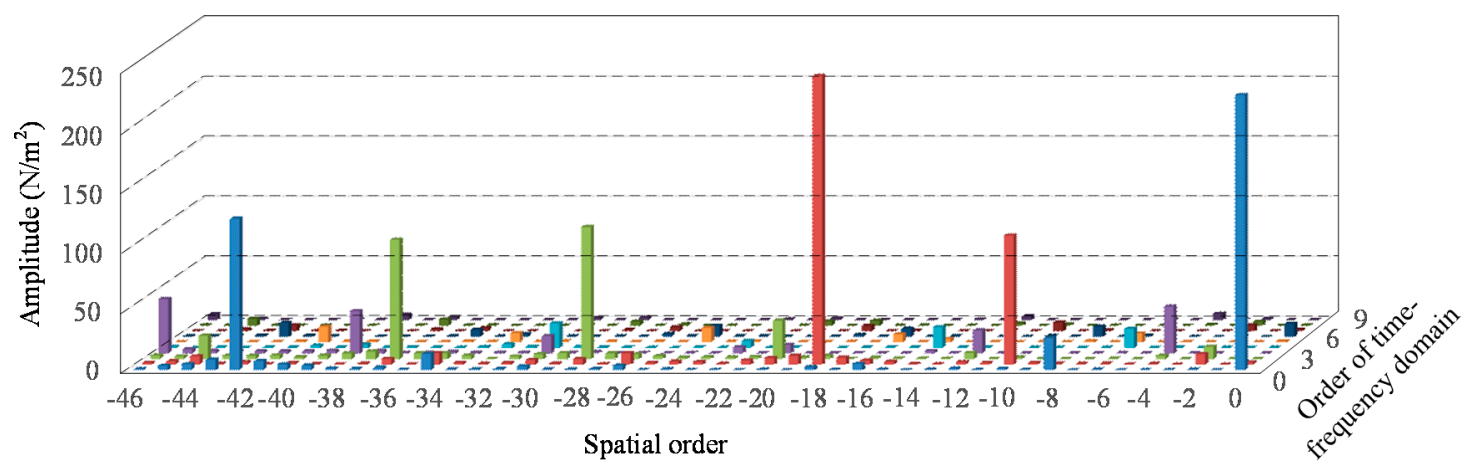

(b)

Figure 5. Orders of radial electromagnetic force: (a) Forward rotation; (b) Reverse rotation.

\section{Structure and Vibroacoustic Analysis}

For the purpose of calculating the electromagnetic vibration and acoustic noise of HTS-FMDS machine, a multi-physics coupling model was established. Firstly, the 2-D transient electromagnetic model was built to calculate the nodal force acting on the surface of the outer stator teeth since this machine has axial symmetry configuration. Then, the nodal force in 3-D model can be obtained according to the periodicity of HTS-FMDS machine under the condition that the electromagnetic force distributes uniformly in the axial direction. Secondly, taking into account the influence of the armature-winding ends, the 3-D structural model of HTS-FMDS machine was built. Additionally, the nodal force was loaded from the electromagnetic model to the structural model by force interpolation. Finally, the modal superposition method was used to calculate the electromagnetic vibration, and the boundary element method was adopted to calculate the electromagnetic acoustic noise.

Figure 6 shows the stator structural model of HTS-FMDS machine. Since the armature windings are fixed in the stator slot by the slot wedges, it is equivalent to a squirrel cage as shown in Figure 6 . Moreover, the equivalent density of this squirrel cage structure is the ratio of actual mass to volume. The equivalent material mechanics parameters of stator core and windings are shown in Table 3. Among of them, Ew and Ec are Young's modulus of silicon steel sheet (200 GPa) and copper (97 GPa), respectively. Gw and Gc are the shear modulus of silicon steel sheet (80 GPa) and copper (32 GPa), respectively. By using FEA, the modal shapes and frequencies of the HTS-FMDS machine can be calculated, as listed in Table 4 . These finite element results of Table 4 reveal that the low-order modal shapes of stator core have two natural frequencies, which are corresponding to in-phase vibration and inverse vibration along the stator axial direction, respectively.

After transferring the electromagnetic force to the stator structural model, the spectrum of vibration acceleration of outer stator can be obtained by using modal superposition method, as depicted in Figure 7. It can be found that the vibration acceleration of the stator surface reach obvious peak value when the electromagnetic force frequencies are $800 \mathrm{~Hz}$ and $1800 \mathrm{~Hz}$, respectively. Corresponding 
to these two peak frequencies, the sound pressure level of the electromagnetic noise, which was calculated by using boundary element method, also reaches peak value, as shown in Figure 8.

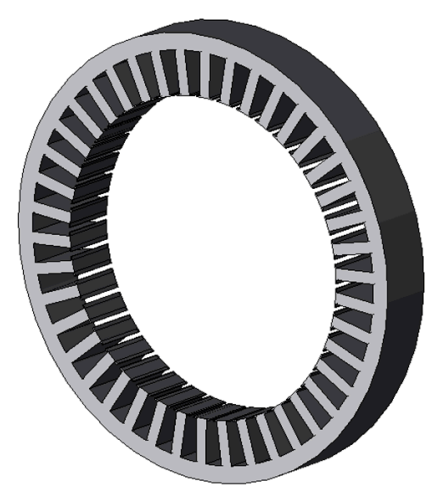

(a)

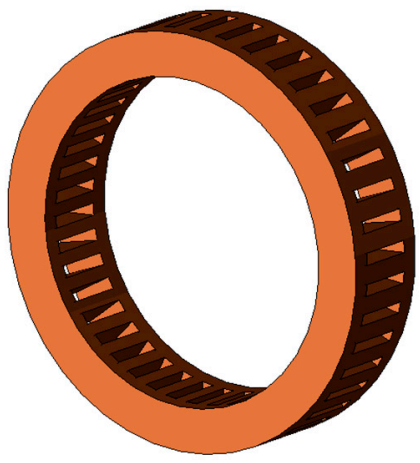

(b)

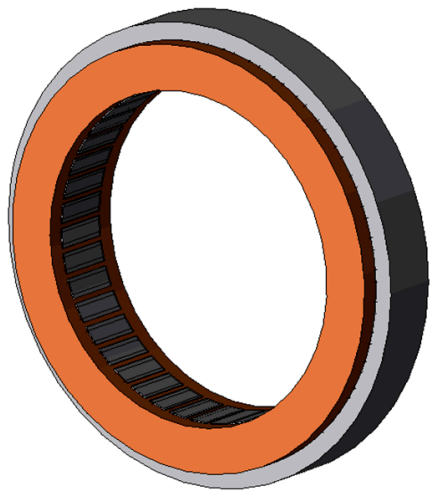

(c)

Figure 6. Stator model of HTS-FMDS machine: (a) Stator core; (b) armature windings; and (c) stator assemblies.

Table 3. Material parameters of stator core and armature winding.

\begin{tabular}{|c|c|c|c|c|}
\hline $\begin{array}{c}\text { Material } \\
\text { Parameters }\end{array}$ & Young's Modulus & Shear Modulus & $\begin{array}{c}\text { Poisson's } \\
\text { Ratio }\end{array}$ & $\begin{array}{l}\text { Density } \\
\left(\mathrm{kg} / \mathrm{m}^{3}\right)\end{array}$ \\
\hline Stator core & $\begin{array}{c}E_{\mathrm{x}}=E_{\mathrm{y}}=0.94 E_{\mathrm{w}} \\
E_{\mathrm{z}}=E_{\mathrm{w}}\end{array}$ & $\begin{array}{c}G_{x y}=0.84 G_{w} \\
G_{y z}=G_{z x}=0.17 G_{w}\end{array}$ & 0.3 & 7488 \\
\hline Armature winding & $\begin{array}{c}E_{\mathrm{x}}=E_{\mathrm{y}}=0.92 E_{\mathrm{c}} \\
E_{\mathrm{z}}=E_{\mathrm{c}}\end{array}$ & $\begin{array}{c}G_{x y}=0.01 G_{c} \\
G_{y z}=G_{z x}=0.02 G_{c}\end{array}$ & 0.3 & 5340 \\
\hline
\end{tabular}

Table 4. Modal shapes and frequencies.

\begin{tabular}{lcc}
\hline Mode Number & Mode Shapes & Natural Frequencies \\
\hline$(2,0)$ & $700.58 \mathrm{~Hz}$ \\
$(3,1)$ & $1127.00 \mathrm{~Hz}$ \\
$(3,1)$ & $1197.71 \mathrm{~Hz}$ \\
$(4,0)$ & $1324.22 \mathrm{~Hz}$ \\
\end{tabular}


Table 4. Cont.

\begin{tabular}{ccc}
\hline Mode Number & Mode Shapes & Natural Frequencies \\
\hline$(4,1)$ & $1644.37 \mathrm{~Hz}$ \\
$(5,1)$ & $1883.20 \mathrm{~Hz}$ \\
$(7,1)$ & $2148.16 \mathrm{~Hz}$ \\
& & \\
$(8,1)$ & $2382.76 \mathrm{~Hz}$
\end{tabular}

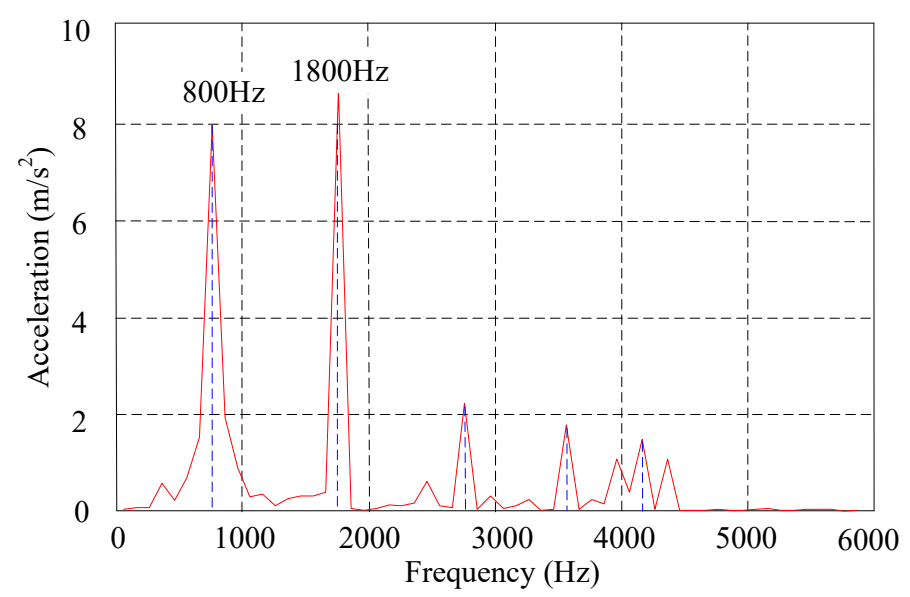

Figure 7. Acceleration spectrum of outer stator surface.

The electromagnetic acoustic noise of the HTS-FMDS machine is produced by the interactions between the harmonic components of electromagnetic forces acting on the stator and all the stator modal shapes. In order to investigate the major contribution of various stator modal shapes to the vibroacoustic at $800 \mathrm{~Hz}$ and $1800 \mathrm{~Hz}$, respectively, the acoustic noise images of HTS-FMDS machine are calculated, as shown in Figure 9. From Figure $9 a$, it can be found that the second order modal shape is the main source of electromagnetic noise when the electromagnetic force frequency is $800 \mathrm{~Hz}$, which agrees well with modal shape and frequency listed in Table 4. Similarly, the fourth order modal shape is the main source of electromagnetic noise when the electromagnetic force frequency is $1600 \mathrm{~Hz}$, 
as illustrated in Figure 9b. Therefore, for the HTS-FMDS machine in this paper, the second and the four order stator modal shapes are the main sources of electromagnetic acoustic noise, although the corresponding second and fourth order electromagnetic force waves, which are shown in Figure 5, have lower amplitudes. In addition, the sound pressure level contour plot also reveals that the strength of low frequency noise is generally higher than that of high frequency noise.

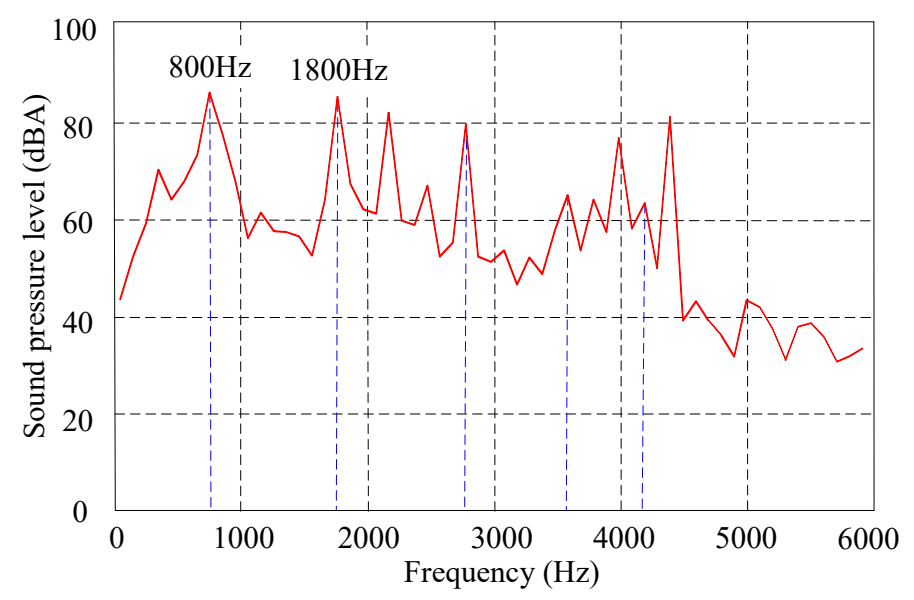

Figure 8. Noise spectrum under rated load.

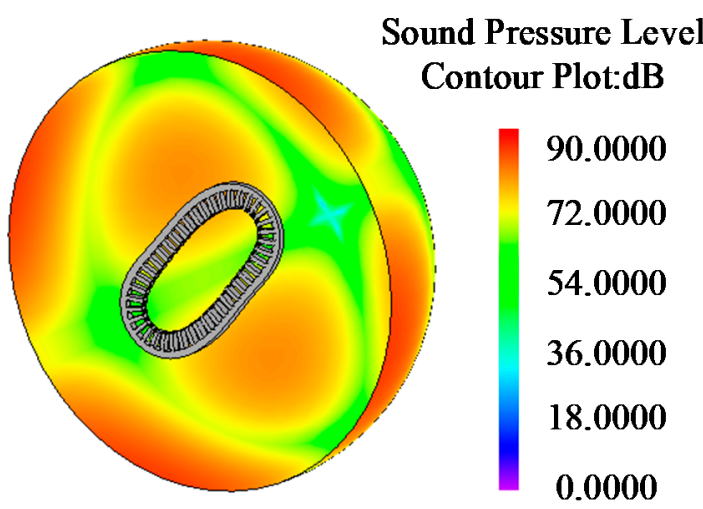

(a)

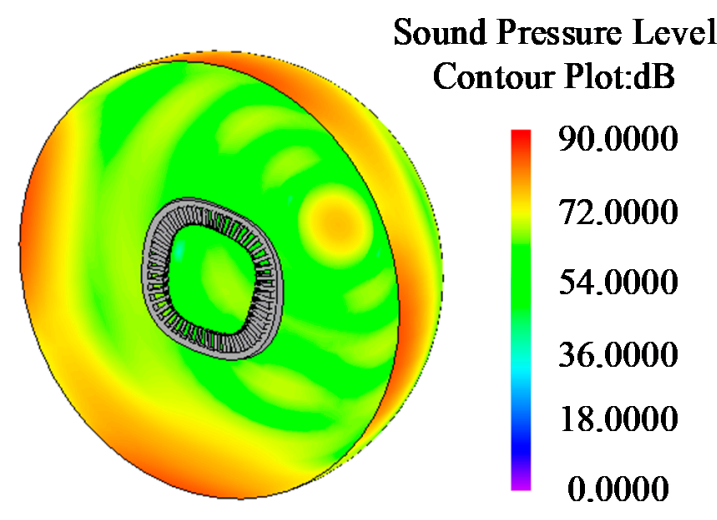

(b)

Figure 9. Acoustic noise image: (a) $800 \mathrm{~Hz}$; (b) $1800 \mathrm{~Hz}$.

\section{Conclusions}

In this work, the vibroacoustic regularity of a HTS-FMDS machine with a stationary seal for low-speed and direct-drive applications were predicted. The spatial order and angular velocity of electromagnetic force density of the HTS-FMDS machine were derived by using analytical method. Moreover, the validity of the analytical solutions is verified by the finite element analysis (FEA) results. Based on the structural modal, the modal shapes and frequencies of the outer stator were obtained by using multiphysics coupling simulation. By transferring the electromagnetic force to the stator structural model, the regularity of electromagnetic vibration and acoustic noise of the HTS-FMDS machine were revealed. For the HTS-FMDS machine in this paper, the second and the fourth order stator modal shapes are the main sources of electromagnetic acoustic noise, although the corresponding second and fourth order electromagnetic force waves have lower amplitudes. In addition, since the electromagnetic force acting on the surface of the stator is rich in harmonic components and high in amplitude, the electromagnetic vibration and acoustic noise of the HTS-FMDS machine are relatively serious. 
Author Contributions: Y.W., C.Z. and W.X. mainly conducted the modal-shapes analysis and theoretical derivation of both air-gaps flux-density and electromagnetic force of HTS-FMDS machine. The manuscript was improved and revised by X.Z. All of the authors contributed to the paper writing.

Funding: This research was funded by in part by the National Science Foundation of China (Projects 51777216 and 51507191), by the Natural Science Foundation of Shandong Province (ZR2018MEE040), by the Application Fundamental Research Funds of Qingdao (Project 17-1-1-28-jch), and by the Fundamental Research Funds for the Central Universities (18CX02114A). The APC was funded by Natural Science Foundation of China (Projects 51777216).

Conflicts of Interest: The authors declare no conflict of interest.

\section{Appendix A}

$$
\begin{aligned}
& \frac{1}{2} \sum_{j=1,3,5 \ldots}^{+\infty} \sum_{J=1,3,5 \ldots}^{+\infty}\left\{\lambda_{\text {ring }, 0}{ }^{2} F_{j} F_{J}\left\{\begin{array}{l}
\cos \left[(j+J) P_{s c} \theta\right] \\
\cos \left[(j-J) P_{s c} \theta\right]
\end{array}\right\}\right\}+ \\
& \frac{1}{4} \sum_{j=1,3,5 \ldots}^{+\infty} \sum_{J=1,3,5 \ldots I}^{+\infty} \sum_{I=1}^{+\infty}\left\{\lambda_{\text {ring, }, 0} F_{j} F_{J} \lambda_{\text {ring, }, I}\left\{\begin{array}{c}
\cos \left[\left((j+J) P_{s c}+I N_{r}\right)\left(\theta-\frac{I N_{r} \omega_{r} t-I N_{r} \theta_{0}}{(j+J) P_{s c}+I N_{r}}\right)\right] \\
\cos \left[\left((j-J) P_{s c}-I N_{r}\right)\left(\theta+\frac{I N_{r} \omega_{r} t-I N_{r} \theta_{0}}{(j-J) P_{s c}-I N_{r}}\right)\right]
\end{array}\right\}+\right. \\
& \frac{1}{4} \sum_{j=1,3,5 \ldots}^{+\infty} \sum_{J=1,3,5 \ldots}^{+\infty} \sum_{I=1}^{+\infty}\left\{\lambda_{\text {ring, }, 0} F_{j} F_{J} \lambda_{\text {ring }, I}\left\{\begin{array}{c}
\cos \left[\left((j+J) P_{s c}-I N_{r}\right)\left(\theta+\frac{I N_{r} \omega_{r} t-I N_{r} \theta_{0}}{(j+J) P_{s c}-I N_{r}}\right)\right] \\
\cos \left[\left((j-J) P_{s c}+I N_{r}\right)\left(\theta-\frac{I N_{r} \omega_{r} t-I N_{r} \theta_{0}}{(j-J) P_{s c}+I N_{r}}\right)\right]
\end{array}\right\}+\right. \\
& \frac{1}{4} \sum_{J=1,3,5 \ldots}^{+\infty} \sum_{j=1,3,5 \ldots}^{+\infty} \sum_{i=1}^{+\infty}\left\{\lambda_{\text {ring }, 0} F_{j} F_{J} \lambda_{\text {ring }, i}\left\{\begin{array}{c}
\cos \left[\left((j+J) P_{s c}+i N_{r}\right)\left(\theta-\frac{i N_{r} \omega_{r} t-i N_{r} \theta_{0}}{(j+J) P_{s c}+i N_{r}}\right)\right] \\
\cos \left[\left((j-J) P_{s c}+i N_{r}\right)\left(\theta-\frac{i N_{r} \omega_{r} t-i N_{r} \theta_{0}}{(j-J) P_{s c}+i N_{r}}\right)\right]
\end{array}\right\}+\right. \\
& \frac{1}{8} \sum_{j=1,3,5 \ldots}^{+\infty} \sum_{i=1}^{+\infty} \sum_{J=1,3,5, \ldots}^{+\infty} \sum_{I=1}^{+\infty}\left\{F_{j} F_{J} \lambda_{\text {ring, }, i} \lambda_{\text {ring }, I}\left\{\begin{array}{c}
\cos \left[\left(j P_{s c}+i N_{r}+J P_{s c}+I N_{r}\right)\left(\theta-\frac{(i+I) N_{r} \omega_{r} t-(i+I) N_{r} \theta_{0}}{j P_{s c}+i N_{r}+J P_{s c}+I N_{r}}\right)\right] \\
\cos \left[\left(j P_{s c}+i N_{r}-J P_{s c}-I N_{r}\right)\left(\theta-\frac{(i-I) N_{r} \omega_{r} t-(i-I) N_{r} \theta_{0}}{j P_{s c}+i N_{r}-J P_{s c}-I N_{r}}\right)\right]
\end{array}\right\}+\right. \\
& \frac{1}{8} \sum_{j=1,3,5 \ldots}^{+\infty} \sum_{i=1}^{+\infty} \sum_{J=1,3,5 \ldots}^{+\infty} \sum_{I=1}^{+\infty}\left\{F_{j} F_{J} \lambda_{\text {ring, }, i} \lambda_{r i n g, I}\left\{\begin{array}{c}
\cos \left[\left(j P_{s c}+i N_{r}+J P_{s c}-I N_{r}\right)\left(\theta-\frac{(i-I) N_{r} \omega_{r} r-(i-I) N_{r} \theta_{0}}{j P_{s c}+i N_{r}+J P_{s c}-I N_{r}}\right)\right] \\
\cos \left[\left(j P_{s c}+i N_{r}-J P_{s c}+I N_{r}\right)\left(\theta-\frac{(i+I) N_{r} \omega_{r} r-(i+I) N_{r} \theta_{0}}{j P_{s c}+i N_{r}-J P_{s c}+I N_{r}}\right)\right]
\end{array}\right\}+\right. \\
& \frac{1}{4} \sum_{J=1,3,5 \ldots j=1,3,5 \ldots}^{+\infty} \sum_{i=1}^{+\infty}\left\{\lambda_{\text {ring, }, 0} F_{j} F_{J} \lambda_{\text {ring }, i}\left\{\begin{array}{c}
\cos \left[\left((j+J) P_{s c}-i N_{r}\right)\left(\theta+\frac{i N_{r} \omega_{r} t-i N_{r} \theta_{0}}{(j+J) P_{s c}-i N_{r}}\right)\right] \\
\cos \left[\left((j-J) P_{s c}-i N_{r}\right)\left(\theta+\frac{i N_{r} \omega_{r} t-i N_{r} \theta_{0}}{(j-J) P_{s c}-i N_{r}}\right)\right]
\end{array}\right\}+\right. \\
& \frac{1}{8} \sum_{j=1,3,5, \ldots}^{+\infty} \sum_{i=1}^{+\infty} \sum_{J=1,3,5, \ldots}^{+\infty} \sum_{I=1}^{+\infty}\left\{F_{j} F_{J} \lambda_{\text {ring, }, i} \lambda_{\text {ring, }, I}\left\{\begin{array}{c}
\cos \left[\left(j P_{s c}-i N_{r}+J P_{s c}+I N_{r}\right)\left(\theta+\frac{(i-I) N_{r} \omega_{r} t-(i-I) N_{r} \theta_{0}}{j P_{s c}-i N_{r}+J P_{s c}+I N_{r}}\right)\right] \\
\cos \left[\left(j P_{s c}-i N_{r}-J P_{s c}-I N_{r}\right)\left(\theta+\frac{(i+I) N_{r} \omega_{r} t-(i+I) N_{r} \theta_{0}}{j P_{s c}-i N_{r}-J P_{s c}-I N_{r}}\right)\right]
\end{array}\right\}+\right. \\
& \frac{1}{8} \sum_{j=1,3,5, \ldots}^{+\infty} \sum_{i=1}^{+\infty} \sum_{J=1,3,5 \ldots}^{+\infty} \sum_{I=1}^{+\infty}\left\{F_{j} F_{J} \lambda_{\text {ring }, i} \lambda_{r i n g, I}\left\{\begin{array}{c}
\cos \left[\left(j P_{s c}-i N_{r}+J P_{s c}-I N_{r}\right)\left(\theta+\frac{(i+I) N_{r} \omega_{\omega_{1}}-(i+I) N_{r_{1}} \theta_{0}}{j P_{s c}-i N_{r}+J P_{s c}-I N_{r}}\right)\right] \\
\cos \left[\left(j P_{s c}-i N_{r}-J P_{s c}+I N_{r}\right)\left(\theta+\frac{(i-I) N_{r} \omega_{r} t-(i-I) N_{r} \theta_{0}}{j P_{s c}-i N_{r}-J P_{s c}+I N_{r}}\right)\right]
\end{array}\right\}\right\} \\
& \overline{8} \sum_{v=1}^{+\infty} \sum_{V=1}^{+\infty} \lambda_{\text {ring, } 0}{ }^{2} F_{\phi v} F_{\phi V}\left\{\begin{array}{l}
\cos \left[(v+V) k P_{s a} \theta+2 N_{r} \omega_{r} t+2 \varphi_{0}-\pi\right] \\
\cos \left[(v-V) k P_{s a} \theta\right]
\end{array}\right\}+
\end{aligned}
$$




$$
\begin{aligned}
& \frac{9}{16} \sum_{v=1}^{+\infty} \sum_{V=1}^{+\infty} \sum_{I=1}^{+\infty} \lambda_{\text {ring, }, 0} F_{\phi v} F_{\phi V} \lambda_{\text {ring, }, I}\left\{\begin{array}{l}
\cos \left[\left((v+V) k P_{s a}+I N_{r}\right)\left(\theta-\frac{(I-2) N_{r} \omega_{r} t-I N_{r} \theta_{0}-2 \varphi_{0}+\pi}{\left((v+V) k P_{s a}+I N_{r}\right)}\right)\right] \\
\cos \left[\left((v-V) k P_{s a}-I N_{r}\right)\left(\theta+\frac{I N_{r} \omega_{r} t-I N_{r} \theta_{0}}{\left((v-V) k P_{s a}-I N_{r}\right)}\right)\right]
\end{array}\right\}+ \\
& \frac{9}{16} \sum_{v=1}^{+\infty} \sum_{V=1}^{+\infty} \sum_{I=1}^{+\infty} \lambda_{\text {ring }, 0} F_{\phi v} F_{\phi V} \lambda_{\text {ring }, I}\left\{\begin{array}{l}
\cos \left[\left((v+V) k P_{s a}-I N_{r}\right)\left(\theta+\frac{(I+2) N_{r} \omega_{r} t-I N_{r} \theta_{0}+2 \varphi_{0}-\pi}{\left.(v+V) k P_{s a}-I N_{r}\right)}\right)\right] \\
\cos \left[\left((v-V) k P_{s a}+I N_{r}\right)\left(\theta-\frac{I N_{r} \omega_{r} t-I N_{r} \theta_{0}}{\left((v-V) k S_{s a}+I N_{r}\right)}\right)\right]
\end{array}\right\}+ \\
& \frac{9}{16} \sum_{V=1}^{+\infty} \sum_{v=1}^{+\infty} \sum_{i=1}^{+\infty} \lambda_{\text {ring }, 0} F_{\phi V} F_{\phi v} \lambda_{\text {ring }, i}\left\{\begin{array}{l}
\cos \left[\left((v+V) k P_{s a}+i N_{r}\right)\left(\theta-\frac{(i-2) N_{r} \omega_{r} t-i N_{r} \theta_{0}-2 \varphi_{0}+\pi}{\left((v+V) k P_{s a}+i N_{r}\right)}\right)\right] \\
\cos \left[\left((v-V) k P_{s a}-i N_{r}\right)\left(\theta-\frac{i N_{r} \omega_{r} t-i N_{r} \theta_{0}}{\left((v-V) k P_{s a}-i N_{r}\right)}\right)\right]
\end{array}\right\}+ \\
& \frac{9}{32} \sum_{v=1}^{+\infty} \sum_{i=1}^{+\infty} \sum_{V=1}^{+\infty} \sum_{I=1}^{+\infty} F_{\phi v} F_{\phi V} \lambda_{r i n g, i} \lambda_{r i n g, r}\left\{\begin{array}{l}
\cos \left[\left(v k P_{s a}+i N_{r}+V k P_{s a}+I N_{r}\right)\left(\theta-\frac{(i+I-2) N_{r} \omega_{r} t-(i+I) N_{N} \theta_{0}-2 \varphi_{0}+\pi}{v k P_{s a}+i N_{r}+V k P_{s a}+I N_{r}}\right)\right] \\
\cos \left[\left(v k P_{s a}+i N_{r}-V k P_{s a}-I N_{r}\right)\left(\theta-\frac{(i-I) N_{r}\left(\omega_{r} r-(i-I) N_{r} \theta_{0}\right.}{v k P_{s a}+i N_{r}-V k P_{s a}-I N_{r}}\right)\right]
\end{array}\right\}+ \\
& \frac{9}{32} \sum_{v=1}^{+\infty} \sum_{i=1}^{+\infty} \sum_{V=1}^{+\infty} \sum_{I=1}^{+\infty} F_{\phi v} F_{\phi V} \lambda_{r i n g, i} \lambda_{r i n g, r}\left\{\begin{array}{l}
\cos \left[\left(v k P_{s a}+i N_{r}+V k P_{s a}-I N_{r}\right)\left(\theta-\frac{(i-I-2) N_{r}\left(\omega_{r} t-(i-I) N_{r} \theta_{0}-2 \varphi_{0}+\pi\right.}{v k k_{s a}+i N_{r}+V k P_{s a}-I N_{r}}\right)\right] \\
\cos \left[\left(v k P_{s a}+i N_{r}-V k P_{s a}+I N_{r}\right)\left(\theta-\frac{(i+I) N_{r} \omega_{r} r-(i+I) N_{r} \theta_{0}}{v k k_{s a}+i N_{r}-V k k_{s a}+I N_{r}}\right)\right]
\end{array}\right\}+
\end{aligned}
$$

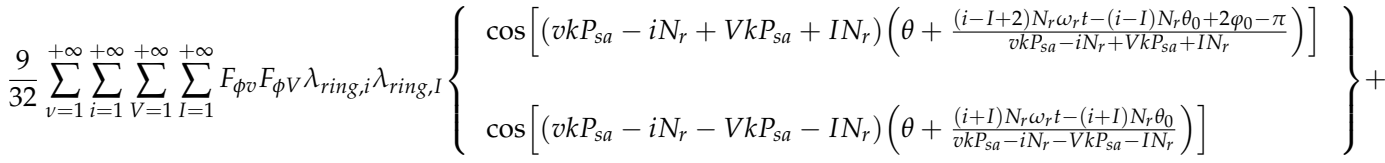

$$
\begin{aligned}
& \frac{9}{16} \sum_{V=1}^{+\infty} \sum_{v=1}^{+\infty} \sum_{i=1}^{+\infty} \lambda_{\text {ring }, 0} F_{\phi V} F_{\phi v} \lambda_{\text {ring }, i}\left\{\begin{array}{l}
\cos \left[\left((v+V) k P_{s a}-i N_{r}\right)\left(\theta+\frac{(i+2) N_{r} \omega_{r} t-i N_{N_{r}} \theta_{0}+2 \varphi_{0}-\pi}{\left((v+V) k P_{s a}-i N_{r}\right)}\right)\right] \\
\cos \left[\left((v-V) k P_{s a}+i N_{r}\right)\left(\theta+\frac{i N_{r} \omega_{r} t-i N_{r} \theta_{0}}{\left((v-V) k P_{s a}+i N_{r}\right)}\right)\right]
\end{array}\right\}+ \\
& \frac{9}{32} \sum_{v=1}^{+\infty} \sum_{i=1}^{+\infty} \sum_{V=1}^{+\infty} \sum_{I=1}^{+\infty} F_{\phi v} F_{\phi V} \lambda_{r i n g, i} \lambda_{r i n g, I}\left\{\begin{array}{l}
\cos \left[\left(v k P_{s a}-i N_{r}+V k P_{s a}-I N_{r}\right)\left(\theta+\frac{(i+I+2) N_{r} \omega_{r} r-(i+I) N_{r} \theta_{0}+2 \varphi_{0}-\pi}{v k P_{s a}-i N_{r}+V k P_{s a}-I N_{r}}\right)\right] \\
\cos \left[\left(v k P_{s a}-i N_{r}-V k P_{s a}+I N_{r}\right)\left(\theta+\frac{(i-I) N_{r} \omega_{r} t-(i-I) N_{r} \theta_{0}}{v k P_{s a}-i N_{r}-V k k_{s a}+I N_{r}}\right)\right]
\end{array}\right\} \\
& \frac{3}{2} \sum_{V=1}^{+\infty} \sum_{j=1,3,5 \ldots}^{+\infty} \lambda_{\text {ring }, 0}{ }^{2} F_{j} F_{\phi V}\left\{\begin{array}{c}
\cos \left(j P_{s c}+V k P_{s a}\right)\left(\theta+\frac{N_{r} \omega_{r} t+\varphi_{0}-\frac{\pi}{2}}{j P_{s c}+V k P_{s a}}\right) \\
\cos \left(j P_{s c}-V k P_{s a}\right)\left(\theta-\frac{N_{r} \omega_{r} t+\varphi_{0}-\frac{\pi}{2}}{j P_{s c}-V k P_{s a}}\right)
\end{array}\right\}+ \\
& \overline{8} \sum_{j=1,3,5, \ldots}^{+\infty} \sum_{V=1}^{+\infty} \sum_{I=1}^{+\infty} \lambda_{\text {ring, } 0} F_{j} F_{\phi V} \lambda_{\text {ring, }, I}\left\{\begin{array}{c}
\cos \left[\left(j P_{s c}+V k P_{s a}+I N_{r}\right)\left(\theta-\frac{(I-1) N_{r} \omega_{r} t-I N_{N_{s}} \theta_{0}-\varphi_{0}+\frac{\pi}{2}}{j P_{s c}+V k P_{s a}+I N_{r}}\right)\right] \\
\cos \left[\left(j P_{s c}-V k P_{s a}-I N_{r}\right)\left(\theta+\frac{(I-1) N_{r} \omega_{r} t-I N_{r} \theta_{0}-\varphi_{0}+\frac{\pi}{2}}{j P_{s c}-V k P_{s a}-I N N_{r}}\right)\right]
\end{array}\right\}+ \\
& \overline{8} \sum_{j=1,3,5, \ldots}^{+\infty} \sum_{V=1}^{+\infty} \sum_{I=1}^{+\infty} \lambda_{\text {ring, } 0} F_{j} F_{\phi V} \lambda_{\text {ring, }, I}\left\{\begin{array}{c}
\cos \left[\left(j P_{s c}+V k P_{s a}-I N_{r}\right)\left(\theta+\frac{(I+1) N_{r} \omega_{r} t-I N_{N_{s}} \theta_{0}+\varphi_{0}-\frac{\pi}{2}}{j P_{s c}+V k P_{s a}-I N_{r}}\right)\right] \\
\cos \left[\left(j P_{s c}-V k P_{s a}+I N_{r}\right)\left(\theta-\frac{(I+1) N_{r} \omega_{r} t-I N_{r} \theta_{0}+\varphi_{0}-\frac{\pi}{2}}{j P_{s c}-V k P_{s a}+I N_{r}}\right)\right]
\end{array}\right\}+ \\
& \frac{3}{8} \sum_{j=1,3,5 \ldots}^{+\infty} \sum_{i=1}^{+\infty} \sum_{V=1}^{+\infty}\left[\lambda_{\text {ring, } 0} F_{j} \lambda_{\text {ring, } i} F_{\phi V}\left\{\begin{array}{c}
\cos \left[\left(j P_{s c}+i N_{r}+V k P_{s a}\right)\left(\theta-\frac{(i-1) N_{r} \omega_{r} t-i N_{r} \theta_{0}-\varphi_{0}+\frac{\pi}{2}}{j P_{s c}+i N_{r}+V k P_{s a}}\right)\right] \\
\cos \left[\left(j P_{s c}+i N_{r}-V k P_{s a}\right)\left(\theta-\frac{(i+1) N_{r} \omega_{r} t-i N_{r} \theta_{0}+\varphi_{0}-\frac{\pi}{2}}{j P_{s c}+i N_{r}-V k P_{s a}}\right)\right]
\end{array}\right\}+\right. \\
& \frac{3}{16} \sum_{j=1,3,5, \ldots}^{+\infty} \sum_{i=1}^{+\infty} \sum_{V=1}^{+\infty} \sum_{I=1}^{+\infty}\left\{F_{j} \lambda_{\text {ring, }, i} F_{\phi V} \lambda_{\text {ring, }, I}\left\{\begin{array}{c}
\cos \left[\left(j P_{s c}+i N_{r}+V k P_{s a}+I N_{r}\right)\left(\theta-\frac{(i+I-1) N_{r} \omega_{r} r-(i+I) N_{N_{r}} \theta_{0}-\varphi_{0}+\frac{\pi}{2}}{j P_{s c}+i N_{r}+V k R_{s a}+I N_{r}}\right)\right] \\
\cos \left[\left(j P_{s c}+i N_{r}-V k P_{s a}-I N_{r}\right)\left(\theta-\frac{(i-I+1) N_{r} \omega_{r} r-(i-I) N_{r} \theta_{0}+\varphi_{0}-\frac{\pi}{2}}{j P_{s c}+i N_{r}-V k P_{s a}-I N_{r}}\right)\right]
\end{array}\right\}+\right.
\end{aligned}
$$




$$
\begin{aligned}
& \frac{3}{16} \sum_{j=1,3,5, \ldots}^{+\infty} \sum_{i=1}^{+\infty} \sum_{V=1}^{+\infty} \sum_{I=1}^{+\infty}\left\{F_{j} \lambda_{r i n g, i} F_{\phi V} \lambda_{\text {ring, }, I}\left\{\begin{array}{c}
\cos \left[\left(j P_{s c}+i N_{r}+V k P_{s a}-I N_{r}\right)\left(\theta-\frac{(i-I-1) N_{r} \omega_{r} t-(i-I) N_{r} \theta_{0}-\varphi_{0}+\frac{\pi}{2}}{j P_{s c}+i N_{r}+V k P_{s a}-I N_{r}}\right)\right] \\
\cos \left[\left(j P_{s c}+i N_{r}-V k P_{s a}+I N_{r}\right)\left(\theta-\frac{(i+I+1) N_{r} \omega_{r} t-(i+I) N_{r} \theta_{0}+\varphi_{0}-\frac{\pi}{2}}{j P_{s c}+i N_{r}-V k P_{s a}+I N_{r}}\right)\right]
\end{array}\right\}+\right. \\
& \overline{8} \sum_{j=1,3, \ldots, \ldots}^{+\infty} \sum_{i=1}^{+\infty} \sum_{V=1}^{+\infty}\left[\lambda_{\text {ring, } 0} F_{j} \lambda_{\text {ring, }, i} F_{\phi V}\left\{\begin{array}{c}
\cos \left[\left(j P_{s c}-i N_{r}+V k P_{s a}\right)\left(\theta+\frac{(i+1) N_{r} \omega_{r} t-i N_{r} \theta_{0}+\varphi_{0}-\frac{\pi}{2}}{j P_{s c}+i N_{r}+V k P_{s a \theta}}\right)\right] \\
\cos \left[\left(j P_{s c}-i N_{r}-V k P_{s a}\right)\left(\theta+\frac{(i-1) N_{r} \omega_{r} t-i N_{r} \theta_{0}-\varphi_{0}+\frac{\pi}{2}}{j P_{s c}-i N_{r}-V k P_{s a}}\right)\right]
\end{array}\right\}\right]+ \\
& \frac{3}{16} \sum_{j=1,3,5, \ldots}^{+\infty} \sum_{i=1}^{+\infty} \sum_{V=1}^{+\infty} \sum_{I=1}^{+\infty}\left\{F_{j} \lambda_{r i n g, i} F_{\phi V} \lambda_{r i n g, I}\left\{\begin{array}{c}
\cos \left[\left(j P_{s c}-i N_{r}+V k P_{s a}+I N_{r}\right)\left(\theta+\frac{(i-I+1) N_{r} \omega_{r} t-(i-I) N_{N_{r}} \theta_{0}+\varphi_{0}-\frac{\pi}{2}}{j P_{s c}-i N_{r}+V k P_{s a}+I N_{r}}\right)\right] \\
\cos \left[\left(j P_{s c}-i N_{r}-V k P_{s a}-I N_{r}\right)\left(\theta+\frac{(i+I-1) N_{r} \omega_{r} t-(i+I) N_{r} \theta_{0}-\varphi_{0}+\frac{\pi}{2}}{j P_{s c}-i N_{r}-V k k_{s a}-I N_{r}}\right)\right]
\end{array}\right\}\right\}+ \\
& \frac{3}{16} \sum_{j=1,3,5, \ldots}^{+\infty} \sum_{i=1}^{+\infty} \sum_{V=1}^{+\infty} \sum_{I=1}^{+\infty}\left\{F_{j} \lambda_{r i n g, i} F_{\phi V} \lambda_{r i n g, r}\left\{\begin{array}{c}
\cos \left[\left(j P_{s c}-i N_{r}+V k P_{s a}-I N_{r}\right)\left(\theta+\frac{(i+I+1) N_{r} \omega_{r} t-(i+I) N_{r} \theta_{0}+\varphi_{0}-\frac{\pi}{2}}{j P_{s c}-i N_{r}+V k P_{s a}-I N_{r}}\right)\right] \\
\cos \left[\left(j P_{s c}-i N_{r}-V k P_{s a}+I N_{r}\right)\left(\theta+\frac{(i-I-1) N_{r} \omega_{r} t-(i-I) N_{r} \theta_{0}-\varphi_{0}+\frac{\pi}{2}}{j P_{s c}-i N_{r}-V k P_{s a}+I N_{r}}\right)\right]
\end{array}\right\}\right\}
\end{aligned}
$$

where $i$ and $I$ are positive integer, $j$ and $J$ are positive odd-number and $v$ and $V$ are the positive integer that cannot be divided by 3 , respectively.

\section{References}

1. Polinder, H.; Ferreira, J.A.; Jensen, B.B.; Abrahamsen, A.B.; Atallah, K.; McMahon, R.A. Trends in wind turbine generator systems. IEEE J. Emerg. Sel. Top. Power Electron. 2013, 1, 174-185. [CrossRef]

2. Yanamoto, T.; Izumi, M.; Yokoyama, M.; Umemoto, K. Electric propulsion motor development for commercial ships in Japan. Proc. IEEE 2015, 103, 2333-2343. [CrossRef]

3. Shafaie, R.; Amirkhanloo, F.; Kalantar, M. Toward an optimum design of large-scale HTS synchronous generator for wind turbine applications. IEEE Trans. Appl. Supercond. 2016, 26. [CrossRef]

4. Kalsi, S.S.; Weeber, K.; Takesue, H.; Lewis, C.; Neumueller, H.W.; Blaugher, R.D. Development status of rotating machines employing superconducting field windings. Proc. IEEE 2004, 92, 1688-1704. [CrossRef]

5. Klaus, G.; Wilke, M.; Frauenhofer, J.; Nick, W.; Neumuller, H.W. Design challenges and benefits of HTS synchronous machines. In Proceedings of the 2007 IEEE Power Engineering Society General Meeting, Tampa, FL, USA, 24-28 June 2007.

6. Kalsi, S.S. Development status of superconducting rotating machines. In Proceedings of the 2002 IEEE Power Engineering Society Winter Meeting. Conference Proceedings, New York, NY, USA, 27-31 January 2002.

7. Gamble, B.; Snitchler, G.; Kalsi, S.S. HTS generator topologies. In Proceedings of the 2006 IEEE Power Engineering Society General Meeting, Montreal, QC, Canada, 18-22 June 2006.

8. Wang, Y.; Wang, C.; Feng, Q.; Li, X.; Ching, T.W. Fabrication and experiment of racetrack HTS coil for stator field-excitation HTS machine. IEEE Trans. Appl. Supercond. 2017, 27. [CrossRef]

9. Wang, Y.; Wang, C.; Feng, Q.; Li, X. Design and experiment of an HTS flux-switching machine with stationary seal. IEEE Trans. Appl. Supercond. 2017, 27. [CrossRef]

10. Wang, Y.; Feng, Q.; Li, X.; Ma, W. Design, analysis, and experimental test of a segmented-rotor high temperature superconducting generator with stationary seal. IEEE Trans. Ind. Electron. 2018. [CrossRef]

11. Li, J.; Song, X.; Cho, Y. Comparison of $12 / 8$ and $6 / 4$ switched reluctance motor: Noise and vibration aspects. IEEE Trans. Magn. 2008, 44, 4131-4134. [CrossRef]

12. Colby, R.S.; Mottier, F.M.; Miller, T.J.E. Vibration modes and acoustic noise in a four-phase switched reluctance motor. IEEE Trans. Ind. Appl. 1996, 32, 1357-1364. [CrossRef]

13. Lin, C.; Fahimi, B. Prediction of acoustic noise in switched reluctance motor drives. IEEE Trans. Energy Convers. 2014, 29, 250-258. [CrossRef]

14. Wu, S.; Zuo, S.; Wu, X.; Lin, F.; Zhong, H.; Zhang, Y. Vibroacoustic prediction and mechanism analysis of claw pole alternators. IEEE Trans. Ind. Electron. 2017, 64, 4463-4473. [CrossRef]

15. Tan-Kim, A.; Lanfranchi, V.; Vivier, S.; Legranger, J.; Palleschi, F. Vibro-acoustic simulation and optimization of a claw-pole alternator. IEEE Trans. Ind. Appl. 2016, 52, 3878-3885. [CrossRef] 
16. Noda, S.; Mori, S.; Ishibashi, F.; Itomi, K. Effect of coils on natural frequencies of stator cores in small induction motors. IEEE Trans. Energy Convers. 1987, 93-99. [CrossRef]

17. Besnerais, J.L.; Lanfranchi, V.; Hecquet, M.; Brochet, P. Characterization and reduction of audible magnetic noise due to PWM supply in induction machines. IEEE Trans. Ind. Electron. 2010, 57, 1288-1295. [CrossRef]

18. Islam, M.S.; Islam, R.; Sebastian, T. Noise and vibration characteristics of permanent-magnet synchronous motors using electromagnetic and structural analyses. IEEE Trans. Ind. Appl. 2014, 50, 3214-3222. [CrossRef]

19. Fang, Y.; Zhang, T. Vibroacoustic characterization of a permanent magnet synchronous motor powertrain for electric vehicles. IEEE Trans. Energy Convers. 2018, 33, 272-280. [CrossRef]

20. Wang, Y.; Yang, G.; Zhu, X.; Li, X.; Ma, W. Electromagnetic Characteristics Analysis of a High-Temperature Superconducting Field-Modulation Double-Stator Machine with Stationary Seal. Energies 2018, 11, 1269. [CrossRef]

21. Cheng, M.; Han, P.; Hua, W. General airgap field modulation theory for electrical machines. IEEE Trans. Ind. Electron. 2017, 64, 6063-6074. [CrossRef]

22. Xiang, Z.; Zhu, X.; Quan, L.; Du, Y.; Zhang, C.; Fan, D. Multilevel design optimization and operation of a brushless double mechanical port flux-switching permanent-magnet motor. IEEE Trans. Ind. Electron. 2016, 63, 6042-6054. [CrossRef]

23. Zheng, P.; Song, Z.Y.; Bai, J.G.; Tong, C.D.; Yu, B. Research on an axial magnetic-field-modulated brushless double rotor machine. Energies 2013, 6, 4799-4829. [CrossRef]

24. Wang, Q.; Niu, S.; Yang, L. Design optimization and comparative study of novel dual-PM excited machines. IEEE Trans. Ind. Electron. 2017, 64, 9924-9933. [CrossRef]

25. Wu, Z.Z.; Zhu, Z.Q. Analysis of air-gap field modulation and magnetic gearing effects in switched flux permanent magnet machines. IEEE Trans. Magn. 2015, 51, 1-12. [CrossRef]

26. Du, Y.; Xiao, F.; Hua, W.; Zhu, X.; Cheng, M.; Quan, L.; Chau, K.T. Comparison of flux-switching pm motors with different winding configurations using magnetic gearing principle. IEEE Trans. Magn. 2016, 52. [CrossRef]

27. Zhu, X.; Fan, D.; Mo, L.; Chen, Y.; Quan, L. Multi-objective optimization design of double-rotor flux-switching permanent magnet machine considering multi-Mode operation. IEEE Trans. Ind. Electron. 2018, 66, 641-653. [CrossRef]

(C) 2018 by the authors. Licensee MDPI, Basel, Switzerland. This article is an open access article distributed under the terms and conditions of the Creative Commons Attribution (CC BY) license (http:/ / creativecommons.org/licenses/by/4.0/). 